\title{
Super Einstein: uma jornada no Sistema Solar rumo ao conhecimento
}

\author{
João Marcelo D. R. Sobrinho ${ }^{1}$, Beatriz B. R. Lucas ${ }^{2}$, Vanessa F. de Almeida ${ }^{3}$, David A. \\ do Nascimento ${ }^{4}$, Hildson D. A. da Silva ${ }^{5}$ \\ 1,2,3,4,5 Campus Garanhuns - Instituto Federal de Educação, Ciência e Tecnologia de \\ Pernambuco (IFPE) - Garanhuns - PE - Brasil \\ \{drsobrinho.jm, beatrzb.ramos, frvanessa.almeida\}@gmail.com \\ \{david.nascimento, hildson.silva\}@garanhuns.ifpe.edu.br
}

\begin{abstract}
Resumo. A educação brasileira atualmente enfrenta dificuldades, decorrentes de diversos fatores, inclusive pelas escolas não obterem êxito em cativar e fomentar os conhecimentos juntos aos alunos. O projeto TechnoEdu, através de suas três ferramentas, traz uma estratégia para atuar em ambos os lados deste processo: o estudante e a instituição de ensino. A partir do aplicativo Super Einstein o estudante será estimulado a responder questões, acumular pontos e percorrer diversos astros do sistema solar. E integrando-o com o WebService e TechnoEduSis, professores e equipe pedagógica poderão propor abordagens diferenciadas, a partir dos dados do jogo. Após experimentos realizados constatou-se a aceitação do Super Einstein pelos estudantes e sua contribuição para a aprendizagem.
\end{abstract}

\section{Cenário de uso}

$\mathrm{Na}$ atualidade, a educação brasileira vem enfrentando dificuldades, sobretudo por não obter êxito em cativar e fomentar os conhecimentos juntos aos alunos. Estudos demonstram que o desinteresse é responsável pela evasão de $40 \%$ dos estudantes de 15 a 17 anos (FGV, 2009). Outro agravante é a evasão escolar: 1,5 milhão de jovens da mesma faixa etária abandonaram a escola (Todos Pela Educação, 2015). A estagnação, desde 2011, da média nacional do Ideb (IDEB, 2015), em 3,7 - calculado em uma escala de 0 a 10 - é um exemplo disso. Observando estes dados, nota-se, de um modo geral, que há déficit de aprendizagem, como também problemas de desinteresse e evasão escolar.

Ao mesmo tempo, também é evidente o amplo uso de novas tecnologias como computadores, celulares e consoles de videogame e, por conseguinte, sua inserção na cultura e no cotidiano (LAZZARO, 2005; McGONIGAL, 2011 apud DE ARAÚJO ROCHA et al.,2009). Pois, com a crescente modernização e democratização destas tecnologias, ocorreu a capilarização de seu uso nos diversos contextos. Uma das repercussões mais claras desse fenômeno são a internet, os smartphones e as redes sociais que vêm ocupando espaço crescente na vida social das mais de 4 bilhões de pessoas conectadas consolidam essa mudança (CIRIADO, 2018). Isto decorre, por exemplo, da capacidade que estas tecnologias têm de envolver seus usuários.

Desta forma, o estudante, habituado a lidar com informações dinamicamente nas redes sociais, encontra-se diante de um sistema de ensino majoritariamente tradicional normalmente um cenário no qual o aluno, num papel coadjuvante, recebe os conteúdos do professor - o que acaba por desestimulá-lo, visto que o modelo está defasado em relação às transformações na sociedade. Mesmo não sendo esse o único fator relacionado aos problemas da educação brasileira, fica evidente - em decorrência de diversos fatores, inclusive os supracitados - que é interessante que as instituições de ensino passem a utilizar novas metodologias, apresentando o conteúdo de forma lúdica (DE ARAÚJO ROCHA et al., 2009). 
Objetivando desenvolver e promover o uso de ferramentas que facilitem o processo de ensino-aprendizagem para estudantes do ensino médio surgiu o projeto TechnoEdu. Neste projeto trabalha-se no desenvolvimento do aplicativo Super Einstein, que é um jogo contempla as diversas disciplinas e os principais conteúdos que fazem parte da grade curricular comum do ensino médio. Através dele, os estudantes poderão testar e reforçar seus conhecimentos por meio de questões, que são aplicadas pela seleção da disciplina e do assunto desejado. Este aplicativo pode ser utilizado em conjunto com as aulas regulares das disciplinas do ensino médio de maneira ao estudante estar em ciclo benéfico de aquisição de conhecimento e verificação de aprendizado com ajudas providas pelo jogo.

O projeto TechnoEdu tem como perspectiva utilizar-se dos dados gerados com os resultados das partidas do Super Einstein que são inicialmente armazenados internamente no celular do estudante e posteriormente enviados para o WebService para se fazer análises e mostrar os resultados através do sistema TechnoEduSis a fim de tornar eficiente o processo de descobrir as lacunas de conhecimento dos estudantes e atuar de maneira mais efetiva no processo de ensino.

\section{Desenvolvimento}

Durante o desenvolvimento do Super Einstein, a equipe utilizou a metodologia de desenvolvimento ágil XP (Programação Extrema, do inglês, Extreme Programming) (MEDEIROS, 2013), o qual foi adaptado e criado o ciclo de trabalho constituído por quatro etapas:

- Planejamento;

- Análise e desenvolvimento;

- Testes; e

- Validação e feedback.

A primeira etapa, planejamento, se inicia com reuniões nas quais são realizados brainstormings (i.e., tempestade de ideias), sobre o que será desenvolvido no ciclo. Partindo para a análise e desenvolvimento, as colocações feitas pela equipe ou pelos entrevistados são filtradas, separadas e documentadas. As que são pertinentes naquele momento passam a ser desenvolvidas. Em seguida passa-se para a fase de testes na qual as novas funcionalidades implementadas são submetidas a testes realizados pela própria equipe com o intuito de verificar seu funcionamento. Quando todo o conjunto de novas funções é desenvolvido, o aplicativo passa pela avaliação realizada pela comunidade - estudantes e professores do IFPE campus Garanhuns. A partir do feedback, é analisado se as novas funcionalidades implementadas devem ser ajustadas ou removidas, como também se outras novas necessitam ser desenvolvidas. Após a conclusão de todas estas etapas inicia-se um novo ciclo.

O Super Einstein, foco principal deste trabalho, é um aplicativo Android desenvolvido em Java utilizando-se da ferramenta Android Studio e banco de dados local SQLite. O WebService é sistema backend desenvolvido em Java utilizando-se da ferramenta Netbeans IDE e faz o armazenamento remoto dos dados de jogo dos jogadores como também das novas questões através do banco de dados PostgreSQL. O WebService troca dados com o Super Einstein e TechnoEduSis através de requisições REST com conteúdo em formato JSON. O TechnoEduSis é sistema web desenvolvido em AngularJS e primeNG.

Para gerenciamento de versões dos códigos e dos desenhos é utilizado o Git e o projeto está hospedado em repositório privado no GitHub. Para modelagem do banco de dados é utilizada a ferramenta BrModelo. E para criação dos desenhos do Super Einstein é utilizada a ferramenta CorelDRAW. 
VII Congresso Brasileiro de Informática na Educação (CBIE 2018)

Anais dos Workshops do VII Congresso Brasileiro de Informática na Educação (WCBIE 2018)

\section{Apresentação do Software}

Dentre os três sistemas que compõem o projeto TechnoEdu, o aplicativo Super Einstein, objeto alvo deste trabalho, já possui uma versão de testes, e para fins de facilidade em sua distribuição na etapa de validação e feedback este aplicativo está disponível em versão beta na loja de aplicativos Google Play, como também disponibilizado no site do projeto: http://technoedu.com.br. Ademais, os seguintes vídeos mostram o funcionamento do aplicativo:

- Por que usar o Super Einstein?: https://www.youtube.com/watch?v=SbVItVAtKNk

- Tutorial - Super Einstein: https://www.youtube.com/watch?v=g-XpewMOjCQ

\subsection{Super Einstein}

Utilizando-se da estratégia da gamificação, que pode ser entendida como o uso de elementos dos jogos envolvendo e motivando os participantes (FARDO, 2013), está sendo desenvolvido o aplicativo Super Einstein. Um jogo em formato de quiz o qual é organizado em cinco estágios - sendo cada um correspondente a um astro, conforme Figura 2a - que representam uma jornada através do Sistema Solar. Nesta empreitada, o jogador é acompanhado pelo Albert Einstein, personagem símbolo do jogo mostrado na Figura 1, respondendo questões de diversas disciplinas e assuntos do ensino médio. O usuário inicia no estágio Saturno, e ao ir acertando diversas questões avança e desbloqueia os próximos estágios que são, respectivamente, Júpiter, Marte, Terra e por fim o Sol, que é último estágio.

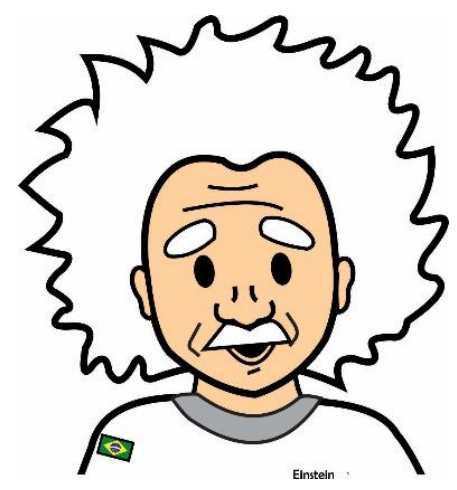

Figura 1 - Albert Einstein: personagem símbolo do jogo. Fonte: Elaborado pelos autores.

As imagens das Figuras 2 e 3 a seguir mostram as telas do aplicativo, o qual na tela inicial (Figura 2a) o usuário pode perceber algumas informações importantes, como o seu estágio atual no jogo, que correspondente ao astro desbloqueado, e o total de sua pontuação representada por XP. Nesta mesma tela, pode-se perceber que os astros podem estar em dois estados: bloqueado, quando o jogador ainda não pode jogar naquele estágio e seu ícone é exibido em tons de cinza, e desbloqueado, quando o jogador pode escolher para jogar naquele estágio e seu ícone é exibido com a imagem colorida. A partir dela também é possível seguir para as demais funcionalidades do aplicativo.

Selecionando-se algum dos planetas desbloqueados, segue-se para a seleção da disciplina, como é mostrado na Figura 2b, e posteriormente na seleção do assunto que se deseja treinar, como mostrado na Figura 2c. Importante salientar que, na tela de seleção de disciplina (Figura 2b), abaixo de cada uma é possível verificar a relação entre a quantidade de questões que o jogador acertou e o total de questões da respectiva disciplina no formato: acertos / total. O mesmo formato é seguido na tela de seleção de assunto (Figura 2c), o qual há também a relação das quantidades de questões que o jogador acertou e o total de questões, mas agora filtrado pelo assunto correspondente. 
VII Congresso Brasileiro de Informática na Educação (CBIE 2018)

Anais dos Workshops do VII Congresso Brasileiro de Informática na Educação (WCBIE 2018)

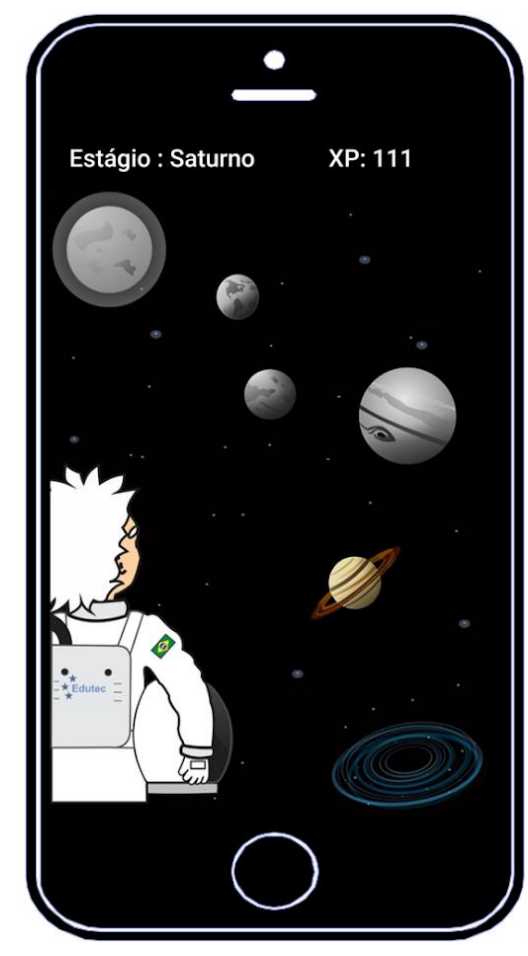

(a)

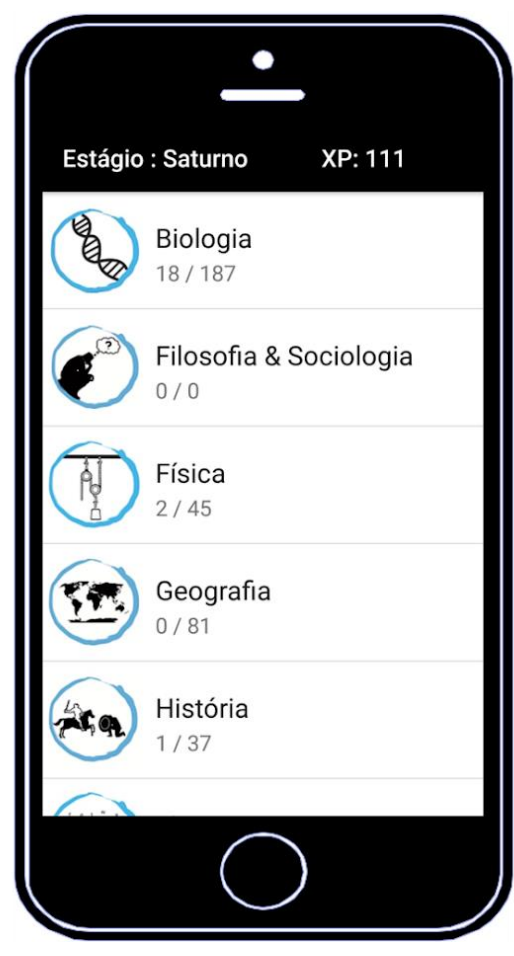

(b)

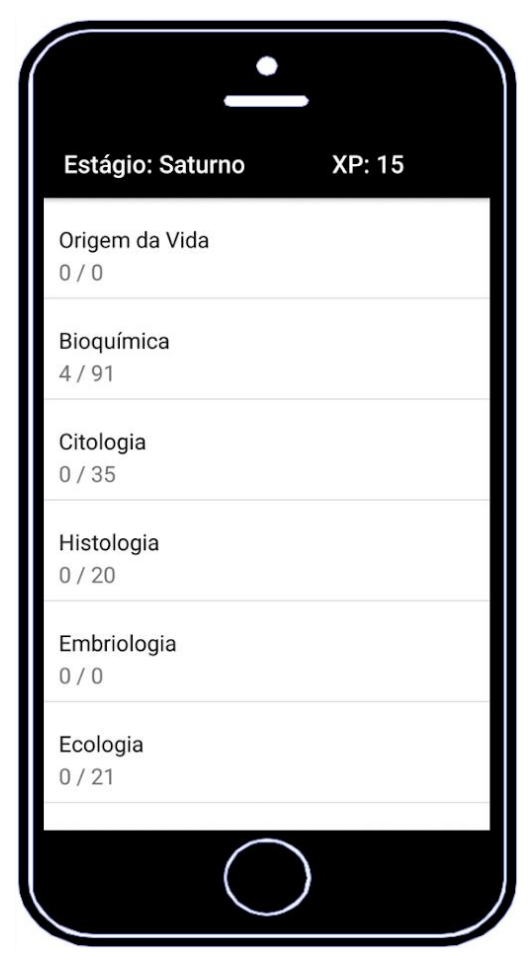

(c)

Figura 2 - (a) Tela inicial. (b) Tela de seleção da disciplina. (c) Tela de seleção do assunto. Fonte: Elaborado pelos autores.

Em seguida, o usuário passa para a tela na qual efetivamente responderá as questões, vide Figura 3a. Uma vez exibida, o jogador possui um tempo determinado para respondê-la, como é mostrado no canto superior esquerdo, de acordo com o nível de dificuldade desta. As questões são divididas em três níveis de dificuldade: fácil, médio e difícil, de modo que possuem, respectivamente, 2, 2,5 e 3 minutos para serem respondidas.

Como mecanismos de ajuda na resolução, o jogador dispõe de três itens de ajuda, cujos ícones estão acima do enunciado (Figura 3a): a eliminação de uma das alternativas erradas, a exibição da dica correspondente a questão e o acréscimo de tempo para responder - o primeiro, o segundo e o terceiro ícone da esquerda para direita, respectivamente. Inicialmente, o usuário tem disponível três ajudas de cada tipo, sendo que na partida pode usar apenas um de cada e, para conseguir um novo item, ele deve responder corretamente a cinco questões seguidas. Para responder, basta um duplo clique sobre sua alternativa-palpite.

A partir da resposta do jogador, é possível que apareçam três tipos de pop-ups. Caso ele acerte a questão, aparecerá uma mensagem parabenizando-o. Caso erre, a mensagem enfatiza a dica para respondê-la corretamente (Figura 3b). E, caso o tempo se esgote sem que o jogador tenha respondido, um pop-up exibe "Que pena, seu tempo acabou".

Interessante ressaltar que, de maneira intencional, logo após a primeira vez que o jogador erra uma questão ele tem a possibilidade de respondê-la novamente. Isso se dá para que o jogador, através da dica que será exibida ao errar, tenha a oportunidade de refletir e acertar sua resposta. Entretanto, caso erre esta questão mais uma vez, outra questão será carregada e exibida.

Outro mecanismo desenvolvido é o modo de distribuição das perguntas. De acordo com o algoritmo do aplicativo, de cada 10 questões que são exibidas para o jogador, prioritariamente, sete ele nunca respondeu - de modo a ampliar seu domínio do assunto escolhido -, duas ele já respondeu e errou anteriormente e uma ele já respondeu e acertou 
VII Congresso Brasileiro de Informática na Educação (CBIE 2018)

Anais dos Workshops do VII Congresso Brasileiro de Informática na Educação (WCBIE 2018)

anteriormente - de modo a contribuir para a revisão dos conteúdos. Caso não existam questões com as características para esse algoritmo, serão escolhidas questões aleatórias, relacionadas ao assunto.

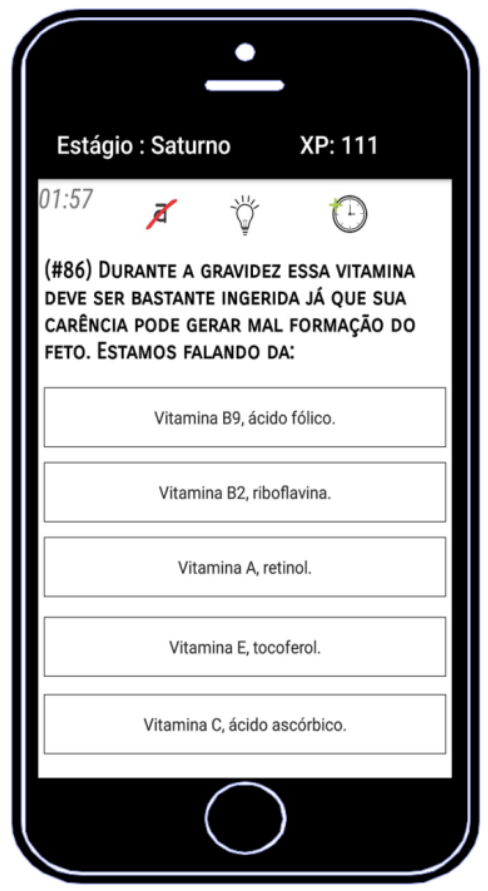

(a)

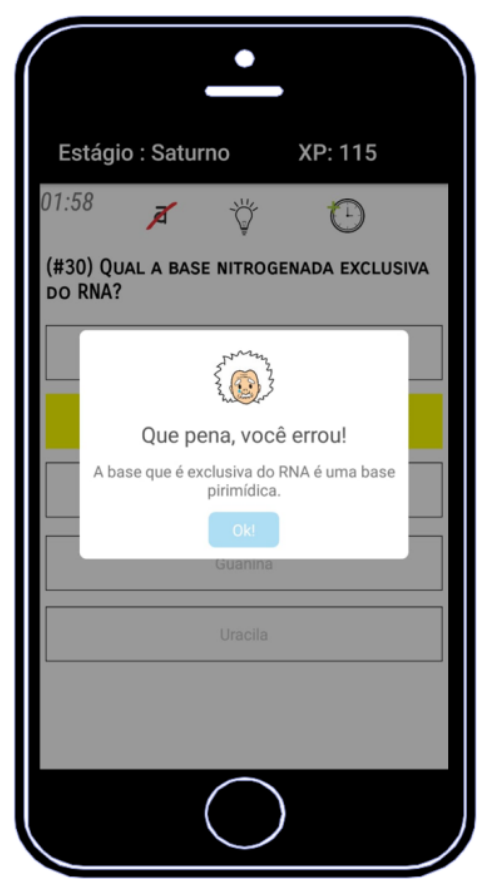

(b)

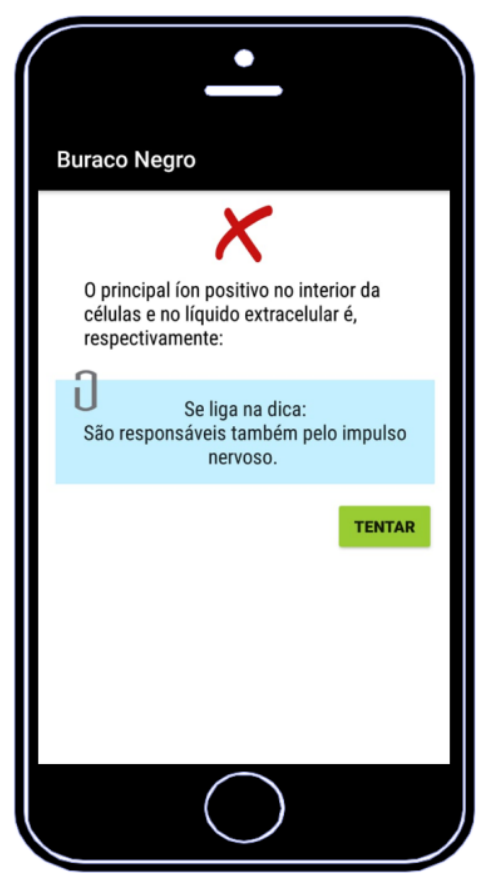

(c)

Figura 3 - (a) Tela para resolução da questão. (b) Tela de questão respondida de maneira errada. (c) Tela de tentar novamente. Fonte: Elaborado pelos autores.

Ao mesmo tempo, voltando a tela inicial, o jogador pode revisar apenas as questões que errou. Clicando no ícone do "buraco negro" no canto inferior direito (Figura 2a), e selecionando a disciplina e o assunto o jogador terá acesso a lista de questões que errou de acordo com o que foi selecionado. Ao escolher uma questão, são mostrados o enunciado e a dica para respondêla (Figura 3c). As alternativas não são exibidas, visto que, sendo o objetivo estimular a aprendizagem, se elas estivessem disponíveis o jogador poderia apenas procurar sua resposta. Dessa forma, o usuário deverá pesquisar e refletir sobre o assunto, para então praticar.

\subsection{WebService}

O sistema WebService é responsável pelo armazenamento remoto dos dados de jogo de todos jogadores como também das novas questões cadastradas que serão disponibilizadas para os jogadores. Para implementação deste sistema está sendo utilizada a linguagem Java e a arquitetura RESTful, em que as requisições são enviadas através de métodos HTTP, e foi escolhido o padrão do conteúdo das mensagens HTTP ser formatado como arquivos do tipo JSON, já que é um padrão simples e bastante utilizado para este fim.

Este sistema suportará, quando completo, as principais operações de manipulação de dados como inserção, atualização, remoção e recuperação, como também recuperações com filtros avançados que serão utilizadas no sistema TechnoEduSis. Escolheu-se este modelo de arquitetura por sua flexibilidade e interoperabilidade na troca de dados entre diferentes plataformas. 
VII Congresso Brasileiro de Informática na Educação (CBIE 2018)

Anais dos Workshops do VII Congresso Brasileiro de Informática na Educação (WCBIE 2018)

\subsection{TechnoEduSis}

O TechnoEduSis é um sistema web, sob desenvolvimento em estágios iniciais até o momento da escrita deste trabalho, que está sendo implementado utilizando as tecnologias AngularJS e primeNG.

Este sistema irá prover todas as informações importantes como também exibir os resultados de análises sobre o desempenho dos estudantes jogadores de modo que professores e equipe pedagógica tenham o pleno conhecimento acerca das dificuldades enfrentadas pelos alunos em cada disciplina e assunto, podendo assim realizar ações mais diretas e efetivas para preencher as lacunas de aprendizado sobre os conteúdos diversos contidos no aplicativo, como também direcionar planos de estudos individuais para cada aluno, já que o sistema irá traçar um perfil individual por aluno, como também por disciplina, turma e por ano escolar. Estes dados e resultados serão exibidos em tabelas e gráficos de maneira a facilitar a interpretação pelos usuários do sistema.

Uma das funcionalidades do TechnoEduSis é o cadastro de novas questões, fazendo assim com que o sistema possa ser sempre alimentado e os jogadores tenham mais disciplinas e assuntos para treinarem seus conhecimentos.

\section{Testes realizados}

Para verificar a usabilidade e a eficácia do aplicativo em desenvolvimento foram realizados alguns testes, organizados em duas categorias: testes de usabilidade e testes para verificação da contribuição no processo de aprendizagem.

Os testes de usabilidade foram realizados de duas maneiras. Na primeira, a equipe abordou professores e alunos apresentando-lhes o aplicativo ou o esboço das próximas funcionalidades. A partir das dificuldades encontradas pelos entrevistados bem como as opiniões coletadas, organizou-se um novo conjunto de ideias de como o aplicativo poderia ser aprimorado. Alguns desses pontos de vista, mediante análise da equipe, foram implementadas e integradas ao aplicativo. A segunda maneira foi a realização de um teste com os estudantes do $1^{\circ}$ ano manhã do curso técnico integrado em informática do IFPE campus Garanhuns. Neste teste, 25 alunos utilizaram o aplicativo durante uma semana. Após este período os usuários foram submetidos a um formulário a partir do qual avaliaram sua experiência com o aplicativo destacando os pontos positivos e negativos, e se voltariam a utilizá-lo. Verificando o formulário aplicado após os estudos foi possível perceber que 100\% dos alunos que responderam e utilizaram o aplicativo a voltariam a utilizá-lo, e acreditavam que ele auxiliará a melhorar seu desempenho.

Nos testes para verificar a contribuição do aplicativo no processo de aprendizagem participaram duas turmas: o $2^{\circ}$ ano manhã e o $2^{\circ}$ ano tarde, ambos do curso técnico integrado em informática, juntas essas turmas totalizaram 47 estudantes participantes dos experimentos.

Cada turma foi dividida em dois grupos - um grupo utilizava o aplicativo e o outro não - e ambos os grupos eram submetidos ao mesmo conjunto de atividades. Inicialmente, os participantes deveriam revisar por 1 hora determinados conteúdos que haviam estudado durante o bimestre vigente utilizando-se de textos de apoio. Em seguida responderam um banco de questões. $\mathrm{O}$ diferencial entre os grupos foi que para um grupo o banco de questões estava no aplicativo e no outro o mesmo banco de questões estava no papel. Por fim, foi realizado um teste impresso sem consulta a nenhum material adicional.

Analisando-se os resultados obtidos com este teste foi possível perceber diferenças. Enquanto o grupo que não estava com o aplicativo reclamou bastante do quão cansativo era ter de responder as questões e ler o material, inclusive ocorreu de alguns dos membros deste teste 
não responderem ou desistirem de realizar a atividade por completo, os outros participantes que estavam utilizando o aplicativo, participaram ativamente de todo o processo e externaram em diversos momentos preferir estudar daquele modo.

Partindo para a análise das pontuações obtidas pelos grupos que utilizaram o aplicativo, esses tiveram acerto de aproximadamente $66 \%$ das questões respondidas, enquanto o outro $56 \%$. Para efeito de nota, essa diferença de $10 \%$, já representaria a "reprovação" - considerando a nota mínima 6 utilizada no IFPE - do segundo grupo, que utilizou uma metodologia tradicional.

\section{Considerações finais e trabalhos futuros}

Percebeu-se, através dos testes e experimentos realizados, diferenças consideráveis entre aqueles que utilizaram o aplicativo e os que não utilizaram, notando-se que o Super Einstein alcança os objetivos esperados, por motivar os estudantes e, por conseguinte, contribuir para o processo de aprendizagem.

Enquanto os estudantes que não utilizaram o aplicativo demonstraram insatisfação com o processo tradicional - no qual apenas faziam uso dos textos de apoio e respondiam as questões no papel - aqueles que estavam com o aplicativo se mostraram mais interessados em continuar estudando, mesmo após o encerramento do tempo do experimento.

Destaca-se que os sistemas do projeto estão em fase de desenvolvimento. Importante salientar que, o objetivo do projeto poderá ser alcançado com plena eficácia, uma vez que todos eles - Super Einstein, WebService e TechnoEduSis - estejam funcionando de modo integrado. Em decorrência disso é necessário ter conhecimento desse tripé para compreender o potencial de inovação do protótipo. Quando em operação, é uma meta, por exemplo, que seja possível ao professor ministrar os conteúdos e, a partir da análise dos dados do Super Einstein no TechnoEduSis, saber quais aspectos precisam de uma abordagem mais enfática.

Como trabalhos futuros estão a finalização de todas as funcionalidades do Super Einstein e TechnoEduSis, como também a completa integração desses sistemas com o WebService. Serão feitos novos experimentos com outras turmas do ensino médio do campus Garanhuns do IFPE, como também de outras escolas da circunvizinhança para validar e melhorar a eficácia do uso do aplicativo no processo de ensino-aprendizagem.

Devida a imensidão de possibilidades de atuações que podem ser feitas para promover o interesse e aprendizado dos jovens estudantes do ensino médio utilizando-se das ferramentas do projeto TechnoEdu, espera-se que, quando o projeto estiver com todas as suas ferramentas desenvolvidas, seja um diferencial no processo educacional a fim de melhorar a educação no Brasil.

Por fim, agradecemos ao Instituto Federal de Educação, Ciência e Tecnologia Pernambuco (IFPE) - Campus Garanhuns que por meio da Pró-Reitoria de Extensão desta instituição contribuiu, através do edital PIBEX-2017, para o desenvolvimento deste trabalho, uma experiência enriquecedora na formação técnica e humanística dos integrantes.

\section{Referências}

CIRIADO, Douglas. (2018). "Mais de 4 bilhões de pessoas usam a internet ao redor do mundo".https://www.tecmundo.com.br/internet/126654-4-bilhoes-pessoas-usam-internetno-mundo.htm. June.

DE ARAÚJO ROCHA, Bárbara Micaela Pereira et al. (2009). RPG UMA NOVA PERSPECTIVA PARA O DESENVOLVIMENTO DO PROCESSO ENSINOAPRENDIZAGEM. 
VII Congresso Brasileiro de Informática na Educação (CBIE 2018)

Anais dos Workshops do VII Congresso Brasileiro de Informática na Educação (WCBIE 2018)

FARDO, Marcelo Luis. (2013). “A gamificação aplicada em ambientes de aprendizagem”. RENOTE, v. 11, n. 1.

Fielding, Roy Thomas. (2000) "Representational State Transfer (REST)". https://www.ics.uci.edu/ fielding/pubs/dissertation/rest_arch_style.htm. June.

G1. (2017). "Brasil possui quase 2,5 milhões de crianças e adolescentes fora da escola, diz estudo". https://g1.globo.com/educacao/noticia/brasil-possui-quase-25-milhoes-decriancas-e-adolescentes-fora-da-escola-diz-estudo.ghtml. June.

MEC (2016). “IDEB: IDEB - Resultados e Metas".http://ideb.inep.gov.br/resultado/. December.

MEDEIROS, Higor (2013). "Introdução ao Extreme Programming (XP)". https://www.devmedia.com.br/introducao-ao-extreme-programming-xp/29249. June.

Sobrinho, João M. D. R.; Lucas, Beatriz B. R.; Almeida, Vanessa F.; Nascimento, David A.; Angelo, Hildson D.; Desenvolvimento e utilização de jogo para smartphone e ferramenta pedagógica como estratégia de melhoria do processo de ensino-aprendizagem no ensino médio. Submetido à Revista Caravana IFPE, Recife, 2017.

TODOS PELA EDUCAÇÃO (2009). "Desinteresse é o principal motivo da evasão escolar dos jovens, afirma pesquisa". http://www.todospelaeducacao.org.br/reportagenstpe/212/desinteresse-e-o-principal-motivo-da-evasao-escolar-dos-jovens-afirma-pesquisa. November 